\title{
How Groups Generate Creative Ideas? Interview with Roni Reiter-Palmon
}

\author{
Roni Reiter-PaImon' and Izabela Lebuda ${ }^{2}$
}

1 University of Nebraska, Omaha, USA,

2 University of Wroclaw, Wroclaw, Poland

\begin{abstract}
In the interview with Roni Reiter-Palmon, one of most prolific creativity researchers, we discuss her career, main areas of research interest, chosen research methods and share her thoughts about the future of research on creativity and effectiveness in scientific work.
\end{abstract}

\section{KEYWORDS:}

Roni Reiter-Palmon, Interview, Researcher

\section{Article history:}

Received: November 3, 2021

Received in revised from: November 3, 2021

Accepted: November 3, 2021

ISSN 2354-0036

DOI: $10.2478 /$ ctra-2021-0020

\section{Corresponding author at:}

Izabela Lebuda

E-MAIL: izalebuda@gmail.com 
Roni Reiter-Palmon is the professor of Industrial-Organizational psychologist and the director of the graduate program at the University of Nebraska at Omaha. Her research focusing on creativity and innovation in the workplace, development of leadership and creative problem-solving skills, and leading creative individuals.

Izabela Lebuda: Please tell me about your professional career; how it happened that among many areas of psychology you took up the psychology of creativity?

Roni Reiter-Palmon: It really was completely by accident. To be honest, when I started graduate school, I wanted to work with Mike Mumford. I didn't know about him before I started, but when I got to the program, I realized that we had some interests that were aligned, particularly interest in individual differences. He had a lot of students at that time, and he was not planning on taking a new one. But when I talked to him, he said "You know, if we're working together, I really want you to work on problem construction". Since I wanted to work with him, even though I didn't know what it was, I said "Okay". He pointed me to a couple of papers, at the time were not many, this was in 1987. And I read all of that and I got really excited. We started to develop our model, which was published in Runco's book in 1994 (Mumford et al., 1994). I got really excited about it. I started completely by accident but here I am. Thirty years later, still doing basically the same, not the same work, but in the same topic - problem construction. I fell in love with the topic.

Izabela Lebuda: Why did you choose Mike Mumford to work with?

Roni Reiter-Palmon: For two reasons. One is, I did not really like some of the other professors that were there. Second, I was really interested in individual differences, and of the professors that I wanted to work with, he was the one that did individual differences. It was not because of his creativity work; it was because he was doing individual differences.

Izabela Lebuda: Could you tell the main areas of your research interests and chosen research method in the psychology of creativity? How did they change over your careers?

Roni Reiter-Palmon: One of the big ones that I'm interested in is what happens before and after idea generation. I started my career with looking at problem identification, problem construction and that interest is still there. Even though there's a lot more research now on that it's still - compared for example to research that looks at divergent thinking or ideation - a drop in the bucket. There's barely anything. Because I'm interested in the cognitive processes of creativity, I then started to look also at what happens after idea generation. This was important too because I was talking to companies, and they were complaining about brainstorming sessions. They come up with 100 ideas and they thought they were done and then nobody did anything. When you have 100 ideas you don't know what to do. But organizations care about what they can implement, and where they can see changes in the organization or changes in products. Over the years I've become interested in groups - how groups generate creative ideas. This is a point where I diverge significantly from Mumford, who does not like studying teams. But also when I was at George Mason University I worked with Stephen Zaccaro, who is a team researcher. I always thought that team creativity was 
interesting and a different phenomenon from individual level creativity. A lot of the problems that we deal with right now are complex and require multiple skills and different areas of knowledge, and that requires teams. The problem was different enough but sufficiently similar, in the sense that I can draw on what we know from at the individual level to understand to the team. A lot of my work focuses on these cognitive processes before idea generation - problem identification, construction, and after idea generation - idea evaluation, idea choice, both at the individual and team level. Now, in addition I have side areas that I'm interested in. As I said, I was always interested in individual differences. I've done some work on the relationship between personality and creativity, intrinsic and extrinsic motivation, growth and fixed mindsets, and creativity at the individual level. And because teams rely on social processes to function, I've started to look at some of the social processes. I'm particularly interested in things like psychological safety in teams that facilitates creativity, reflection, and reflexivity in teams, and how that relates to creativity. That's kind of in a broad nutshell, where I'm at. Methods - I do a lot of basic research, focusing on surveys, experimental design. Also, when I have the chance to go into organizations and collect data there, I'm happy to do that as well. But those are usually a little bit more difficult.

\section{Izabela Lebuda: What're your primary motives to choose new directions in creative studies?}

Roni Reiter-Palmon: Yeah, that's a great question. There were some things that I'm more intrinsically interested in. I also know that I tend to view things through my own lens, so my own research leads me to think about creativity in a certain way because that's the way I think about creativity. I potentially have some blind spots. I potentially have some areas where I focus on certain things. I always think about applicability, but again that's my Industria/Organiational psychology training. Anytime we do something whether I do the same with my students: "Okay, you did this basic research in the lab but what would you take to an organization, what did we learn from it that we can apply?". Even though it's not necessarily always applied in an organization I always think about how we can apply it. And I think that's one of the reasons I really enjoy doing the research on the cognitive processes. Those are easily applicable. If we find that telling people to think about the problem and restate it in multiple ways allows them to come up with more creative solutions - I have a piece of advice that I could give people. I could go into an organization and say "Before you start thinking about solution take 10 minutes, think about what the problem is, restated in different ways. Now let's think about the solution". Those translate nicely into applied tips that I could, and I've used in executive education or workshops for organizations.

\section{Izabela Lebuda: Why do you think it's worth researching creativity?}

Roni Reiter-Palmon: Yeah, a few things. First of all, when I started studying creativity in the late 80 s. I actually had people come to me and say, (and these were, senior people in the field and here I am a graduate student): "Why are you studying creativity? Organizations don't care about creativity. Organizations need routines". I was like "Okay, whatever". At some point in the 90s creativity and innovation became sort of the golden standard, so I don't get a lot of "Why are you studying creativity?" now. I put it in the organizational context and people go "Creativity and innovation are important for organizations, we need that". We see everything that's happening in tech and so forth. Even 
with COVID-19. One of the things that I was looking for during COVID, were some interesting ways of coming up with solutions to problems. For example, like medical issues, there was a hospital in North Carolina, that found a way to divide the airflow from ventilators to three or four. When you have a shortage of ventilators, that becomes a big deal. This was a creative way of extending what the ventilator can do. And then it was implemented, not just in that hospital, but also in others hospital. Some people came up with a great way of reusing the N-95 masks. So usually, you use them and then you throw them away because you know they're unsanitary. They were sanitizing them using, I believe, UV-rays or X-rays or something, some rays. I'm not quite sure which ones, but they were able to sanitize them, and reuse them. Again, when we had an issue of shortage of these N- 95 masks, that was a big deal. I think, even when we have complex problems like Covid there is a room for creativity. How was this vaccine developed? Somebody had to develop the groundwork of the mRNA. That was creative at the time. It may not be creative today because it's been in existence for a while. This is the first mRNA a vaccine that we have. And now they're thinking about using it for cancer, and for AIDS. To me, all these things, these scientific breakthroughs, these organizational approaches that use creativity and innovation to solve these big problems, that's where creativity matters to people.

Izabela Lebuda: What currently do you see the most crucial and most fascinating areas of research on creativity?

Roni Reiter-Palmon: I think understanding scientific creativity and understanding how teams of interdisciplinary scientists work to come up to develop creative ideas to complex and important problems, is something that we need to pay attention to. We really don't know enough about the creativity specifically in the science domain, and we really don't know enough about team creativity of interdisciplinary teams. But I think those interdisciplinary teams are what are going to be responsible for the major innovations that we're going to see. I'm personally very interested in doing some work in team creativity. More broadly. If you look at the team creativity research. It started out as people, individuals, how does the team facilitate individual creativity. It's moved toward the team being the unit of analysis. Now of course, teams are much harder as a unit of analysis because even if we do it in the lab, which I'm trying to do, if you have one participant show up for a team study, forget it. We can't use the data. You need to have at least three people show up to have a team. It makes data collection a lot more difficult, so we really have a shortage of team studies, and the team studies that we do tend to have focus on the social processes or brainstorming. We don't have a good understanding of problem construction and teams. We have some but it's limited. We have some but again very limited on idea evaluation and idea choice by teams. And we really don't understand, and that's something that I'm working on. Right now, we have a National Science Foundation (NSF) grant to study interaction between the social and the cognitive processes that are happening. Till now we don't understand how those two interact and they relate to each other. So, that's right now my fascination.

Izabela Lebuda: What do you think, the direction in which the psychology of creativity will devel$o p ?$ 
Roni Reiter-Palmon: There are the kinds of things that I see because of reviewing manuscripts and being an editor. Right now, people say, "covid and well-being". It's important to understand what's the relationship between creativity and well-being. That's coming up quite a bit. And I'm not surprised again COVID-19 I think changed our thinking. I think creativity and neuroscience is booming and I find that interesting even though I really don't understand the neuroscience piece of it. I think that area is growing and that's good. One of the things that I noticed in early neuroscience research was that the people doing the neuroscience work or not familiar with creativity, so they were using thing measures that were not necessarily appropriate. Now we have people that are in creativity research and doing neuroscience of creativity and I think the work is much better, and more interesting as a result. I think focusing on an education and training, both education for students in the schools, as well as training in the workplace and developing employees, there's an area that's going to get attention. I'm fascinated personally by all the changes that we're seeing in the workplace. One of the things that I'm looking at again given my fascination with tools. We have very little about creativity and virtual teams, I've had online meetings for over a year. We're doing creative work, we're scientists. How does that work, when is it successful, when is it not successful? Now, in a lot of organizations, we're moving toward to hybrid teams. How do the technology tools that we have influenced the creative process? I was just working on a paper on this issue and of virtual teams, and I saw a paper that looked at cognitive processes and teams in virtual reality and I was all excited. And then I saw that it was from 2011. That was the last one I found! But we have so many more tools now, you could use a whiteboard, share documents, put stuff in the chat, that didn't exist 10 years ago. The technology is outpacing our research, and we don't have an understanding of how that technology facilitates or hinders creativity. I'm not going to say I know one way or the other. And especially the different processes, what happens to problem construction? What happens in idea generation, what happens in terms of idea evaluation and idea choice?

Izabela Lebuda: You are the one of the most prolific creativity psychologists. Can you share your advice, principles of effectiveness in scientific work?

Roni Reiter-Palmon: First of all, I think the fact that I'm doing stuff that I love, I'm researching areas that I'm really interested, makes a big difference. My husband laughs because he come upstairs at $6 \mathrm{pm}$ and still working. When I get into what I'm doing it doesn't feel tiring. At the end of the day, it's tiring at the time, but sometimes it doesn't feel like work. Find a topic that you enjoy doing work on. I say this as someone who was told that I will not be successful as an academic and I will not publish studying creativity. Again, remember this is late 80 s early 90 s when creativity was not big deal. It took a while and it became important, but I did not listen, I did not follow the advice of research something that will get you published, I research something that was important for me. I also love to collaborate with other people. I learned a lot from those collaborations, they also make me more productive. When you have somebody to be accountable to, whether it's a student that needs a publication to get a job, whether it's a colleague that needs a publication, or even if they don't, the fact that you're accountable to somebody else tends to help. I think it makes it more fun. Sitting by myself and doing all the work by myself is not fun, doing it in a group to me is much 
more fun, and again I learn a lot. I write when I can. I learned a long time ago that I don't have a full day to devote to writing. It just doesn't happen. I have three two or three hours, I blocked it. It is one of the best pieces of advice from Paul Silvia, and his book How to write a lot (2007), which I strongly recommend. Blocking time for reading and making sure that you stick with it. If I need to be in a meeting during my writing time I make sure that I find a substitute time for writing. I dedicate a few hours a week, a certain amount of time for writing. I also learned to use small time periods. I have half an hour between this meeting and that meeting. Well in half an hour I could read an abstract and decide if it's relevant to my research, or I could start working on my reference list or I can read a paragraph and revise it, maybe I can't write a whole paragraph. But there are pieces that I could do. Learning to fit the tasks that you have to the timeframe that you have, is really important. And then, frankly, I had a great environment. I have a husband who's incredibly supportive my job and my profession. Especially when my children were little. He allowed me the time to work. He did his part so I could have the time to work. I have a department that's very supportive. I know some departments; you must publish in certain journals and if you don't, it doesn't count. In our departments if this is a good journal, we're okay with it. I published much of my work in creativity journals, and they were fine with it. And in fact, there was a survey a couple of years ago that showed that the IO program in our department had the most interdisciplinary publication record with across a wide variety of journals, not just in IO traditional journals, which I think is important. But it also gives you the freedom to work on what you enjoy, as well as trying to find a place to publish articles, and that's another trick is. If you wrote a manuscript, and it gets rejected from one place, don't give up! Read the reviews, modify the paper based on what the reviews say, and then submitted somewhere else. There are multiple journals that you can submit. Because you got a rejection and not great reviews doesn't mean it's not fixable. You know sometimes fixing it just means rewriting it, sometimes it means doing another study and resubmitting. Don't give up if it's a good idea, and if it's a good project. Sometimes I've had articles where we found that home after four or five different tries. And that's okay!

Izabela Lebuda: When you think about young scientists, do you think the better idea is to focus on the one area of creativity research or go broadly?

Roni Reiter-Palmon: It's somewhere in the middle. I have multiple areas of interest, and I've always had. But they're all connected. I think having multiple areas, if you don't want to be spread too thin, but you also don't want to have a very niche area, either. So having two or three streams of research is probably not a bad idea, but it also depends on the person, and whether that is manageable, though. Some people prefer to have it more narrow or that fits with their approach to science better. I would say that probably more important is for young scientist is not necessarily how many areas but rather where are things in the pipeline. You always want to have things in different stages of development, so you want to have the article you're writing right now so where everything's done and you're just writing. You want to have that project that you're in the data collection or data analysis stage, or one or two of those and then the one project, or one or two projects that you're developing. Because as you finish writing that one article that you're writing, you want to have 
been able to move to the next writing. So, you must have a paper that's ready to be written so you always want to have things in the pipeline for you, so that you always have the next thing ready.

Izabela Lebuda: I have one more question about your whole career. Do you think that gender has some role in your career?

Roni Reiter-Palmon: You know that's a tough one. So first let me say that when I was a graduate student, most IO professionals, faculty and scientists, were male. Almost all the faculty that I worked with, and were in the program, were male. I had no one to look up to and go, this is how you could be a female IO psychologist in academia. Moreover, I wanted children. I had no one to look at to figure out how do you manage career and children that could give me advice. It's changing, has changed quite a bit, we have female faculty. In fact, our program right now our incoming faculty are majority women in the IO program, which is great. I had my first child during graduate school and I had a lot of support from the faculty, from Mike Mumford from Steve Zaccaro, and other faculty at George Mason. I really was very lucky. I didn't get comments that I heard other people get like you know you're crazy for having a child. I was told that it's going to take me longer to finish if I decide to have a child because you have an added responsibility. It didn't take me that much longer. But again, I also had a lot of help from my husband. I was not alone in doing this. We didn't get comments like my mother got in the 60s. She had me while she was working on her $\mathrm{PhD}$, and she got asked if she was leaving the program. Nobody asked me to leave the program, which was good. That's an improvement. But I also made some choices based on the fact that I had a child. When I finished my PhD, I selected a position that I knew would not require me to publish crazy amounts, or try to get grants, necessarily. Grants were great, but if I didn't get them, I could still get tenure. I don't know if men have those considerations. Some probably don't. Some do. I did. Part of my decision making was based on a place that would allow me to still have my family. We didn't have a lot of females in the department at the time. I think I was the fourth female faculty, out of 18, or 19. I was the first female full professor in our department. I think I was in a place where I was appreciated and supported in terms of department. I know many women are not. I had an advisor that was incredibly supportive. I know many women do not. So, to some extent, I was in the right place at the right time and that helped. What I try to do now is pay attention to what can I do to facilitate, especially young women scientists. Make sure that if I see something in the environment that is sexist, misogynistic, that I speak up. I have to say that in creativity in general when I go to conferences like APA division 10 things are amazing. The senior scientists are always come to the poster sessions and they talk to the younger folks, and they're very encouraging, and they're very supportive and you don't have that in every division and you don't have that in every domain so I don't know if it's something to with the people that study creativity are different. I don't know if that's kind of the tradition that we've developed. But I appreciate that, and I think that support from senior scientists to younger scientists, male or female, is important, but for female scientists in particular.

Izabela Lebuda: I would like to ask you about your plans in creativity research.

Roni Reiter-Palmon: So, as I mentioned, I'm working on this NSF grant. We just finished study one out of three. For the next two years that's really a lot of my work is focusing on, on this understand- 
ing of the interplay between social and individual processes. Then I want to take that further as I mentioned, into virtual teams and hybrid teams. Understand what is happening, both in terms of the social and the cognitive processes. I think we need to look at both, and we need to look at both in that dynamic way. So, how that will fully develop, I'm not quite sure. And also, when things come up I like to be able to say "Yes". If people approach me with opportunities for collaboration, I want to have the bandwidth to say "yes", if it's an interesting project, and if it's a person that would be working with. Those are not predictable, I don't know when people will approach me, but I find that I get some of the best research and most enjoyment out of this, especially when it's some of the younger folks. I try to learn from every collaboration that I have. Both in terms of developing my skills in terms of enhancing my knowledge. So, I leave myself some room for that.

\section{References:}

Mumford, M.D., Reiter-Palmon, R., \& Redmond, M.R. (1994). Problem construction and cognition: applying problem representations in ill-defined domains. In M. Runco (Ed.), Problem Finding, Problem Solving, Creativity (3-39). Ablex.

Silvia, P.J. (2007). How to write a lot: A practical guide to academic writing. American Psychological Association.

(c) Copyright by Faculty of Education, University of Bialystok,

20 Swierkowa St., 15-328 Bialystok, Poland

tel. +48857457283

e-mail: creativity@uwb.edu.pl

http://www.creativity.uwb.edu.pl 